\title{
Measurement of bronchial blood flow in the sheep by video dilution technique
}

\author{
DP LINK, GH PARSONS, BMT LANTZ, RA GUNTHER, JF GREEN, CE CROSS \\ From the Departments of Diagnostic Radiology, Internal Medicine, Surgery, and Human Physiology, \\ University of California, Davis, California
}

\begin{abstract}
Bronchial blood flow was determined in five adult anaesthetised sheep by the video dilution technique. This is a new fluoroscopic technique for measuring blood flow that requires only arterial catheterisation. Catheters were placed into the broncho-oesophageal artery and ascending aorta from the femoral arteries for contrast injections and subsequent videotape recording. The technique yields bronchial blood flow as a percentage of cardiac output. The average bronchial artery blood flow was $0.6 \%$ (SD $0.20 \%$ ) of cardiac output. In one sheep histamine $(90 \mu \mathrm{g})$ injected directly into the bronchial artery increased bronchial blood flow by a factor of 6 and histamine $(90 \mu \mathrm{g})$ plus methacholine $(4.5 \mu \mathrm{g})$ augmented flow by a factor of $7 \cdot 5$ while leaving cardiac output unchanged. This study confirms the high degree of reactivity of the bronchial circulation and demonstrates the feasibility of using the video dilution technique to investigate the determinants of total bronchial artery blood flow in a stable animal model avoiding thoracotomy.
\end{abstract}

Recent advances in the techniques of therapeutic embolisation for control of haemoptysis in patients with severely compromised lung function' and after lung transplantation ${ }^{2}$ have rekindled clinical interest in the bronchial circulation. This interest in the airway blood flow is buttressed by the certainty that the circulation must play a role in airway water and heat exchange $e^{4}$ and the likelihood that it plays a part in other airway functions. ${ }^{5}$ Older publications contain many elegant studies of this lesser lung circulation, ${ }^{6-10}$ including the measurement of bronchial artery blood flow (QB) in animals and its physiological and pharmacological reactivity. ${ }^{1-14}$ Many of these studies used invasive techniques, however, including extensive intrathoracic surgery, and may not have reflected normal conditions. More recent studies using microsphere ${ }^{15-18}$ and flowmeter ${ }^{19}$ techniques have measured bronchial artery blood flow, but with somewhat discordant results.

Although many different techniques have been used to assess bronchial blood flow in animals none of them is entirely satisfactory. ${ }^{14}$ For example,

Address for reprint requests: Dr CE Cross, Division of Pulmonary Medicine, Department of Medicine, 4301 X Street, Sacramento, California 95817, USA.

Accepted 14 September 1984 recently reported techniques for studying QB require either thoracotomy and mediastinal dissection $^{19}$ or injections of radioactive microspheres with subsequent need to obtain airway and lung parenchymal tissues. ${ }^{15-18}$ An added complexity is that in most large experimental animals, and in man, several small bronchial arteries derived from the aorta or intercostal vessels contain the total QB. ${ }^{40}$

A new video dilution technique has recently been developed as a relatively non-invasive method for measuring regional blood flow. ${ }^{21}$ In the present study the technique was used to determine QB. Sheep were used because most of the airway blood supply in this species is delivered by a single vessel that arises from the proximal, concave part of the descending thoracic aorta. ${ }^{20}$ The aortic origin of this vessel is the broncho-oesophageal artery. Immediately after leaving the aorta one or more small and variable oesophageal vessels branch off, leaving the larger vessel (the carinal artery) passing to the posterior wall of the trachea near the carina. This vessel supplies blood flow to the lower trachea and to about $90 \%$ of the sheep airways ${ }^{19}$ and is henceforth referred to as the bronchial artery. Its flow distribution has been fairly well characterised anatomically. ${ }^{19} 20$ This vessel can easily be catheterised under fluoroscopic control. ${ }^{22}$ 


\section{Methods}

PREPARATION AND PROCEDURES

Five castrated male sheep $(36-45 \mathrm{~kg})$ were anaesthetised with thiamylal $10-15 \mathrm{mg} / \mathrm{kg}$, intubated, ventilated with a mixture of $1-2 \%$ halothane and oxygen, and paralysed with succinyl choline $15 \mathrm{mg} /$ kg. A Swan-Ganz catheter was placed in the pulmonary artery for frequent determinations of cardiac output by thermal dilution. The right carotid artery was catheterised to monitor heart rate and arterial pressure. A 7 French gauge high flow pigtail catheter (Cook) was introduced under fluoroscopic control into the aortic root via the right femoral artery. A 5 French gauge catheter (Cook) was then introduced via the left femoral artery and manipulated into the broncho-oesophageal artery at the origin of the bronchial artery. Rectal temperature and blood gas tensions were monitored at frequent intervals. After contrast injections (diatrizoate meglumine and diatrizoate sodium) into the bronchial artery and the aortic root a bronchial artery branch was monitored under fluoroscopic control with locked voltage $(60 \mathrm{KVp})$ and amperage (3.5 MA). Oesophageal arterial branches were small and sometimes not even visualised by our angiographic technique. The fluoroscopic image of the bronchial artery was simultaneously recorded on $3 / 4^{\prime \prime}$ video cassette (Sony). A three phase constant potential $x$ ray generator connected to a triple mode caesium iodide image intensifier was used. Q́B was determined in all five sheep by the video dilution technique (see below) as a percentage of cardiac output. In one sheep Q̇B was determined after bronchial arterial injections of adrenaline, histamine, and methacholine in concentrations insufficient to affect peripheral haemodynamics. Single $0.5 \mathrm{ml}$ doses of contrast agent were injected manually into the broncho-oesophageal artery via the selective catheter with a tuberculin syringe. Three or four injections of $20-40 \mathrm{ml}$ were made alternately into the aortic root catheter by angiographic pressure injector (Cordis) at $1000 \mathrm{lb} / \mathrm{in}^{2}(6900 \mathrm{kPa})$. Throughout the experiments the animal and fluoroscope were in a fixed position. All injection images were videotaped in the same phase of suspended respiration (end expiration). The videotape was replayed after the experiments and QB was determined by a digital video densitometer, VDT Mark I (Angiotec).

The position of the catheter in the bronchooesophageal artery at the origin of the bronchial artery was documented on film by digital subtraction (ADAC) after injection of $4 \mathrm{ml}$ of a $25 \%$ solution of contrast agent into this vessel (fig 1). Before the animals were killed methylene blue was injected through the selective catheter. The bronchial

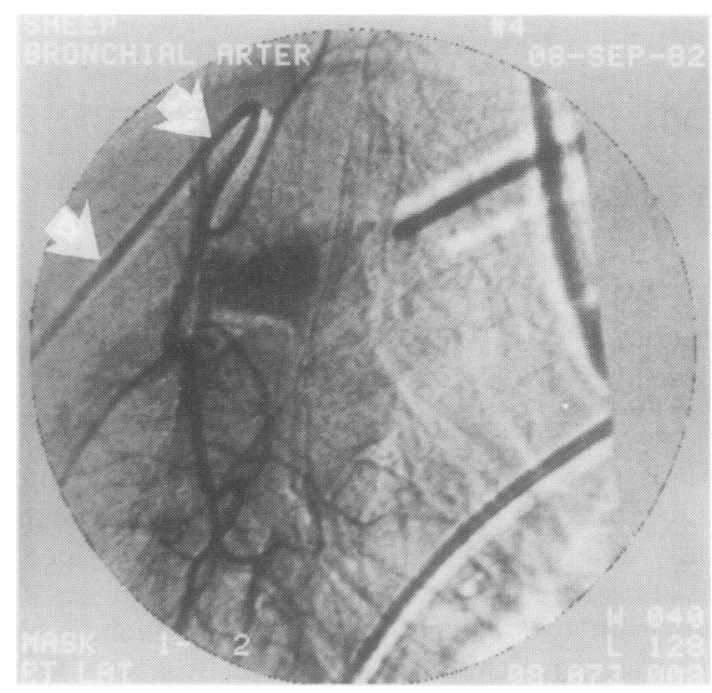

Fig 1 Bronchial arteriography by digital subtraction technique showing catheter position in the broncho-oesophageal artery.

arteries were then dissected post mortem to verify both catheter placement and the extent of the bronchial aterial distribution. Typically, the dye was distributed to the lower trachea and to the airways of all lobes and visceral pleura with the exception of the right upper lobe airways, which received variable perfusion from this vessel.

\section{VIDEO DILUTION TECHNIQUE}

The video dilution technique is an indicator dilution technique using angiographic contrast medium as the flow indicator. Density changes in the fluoroscopic image caused by intra-arterially injected contrast medium are recorded by a digital electronic densitometer with a linear output. For densitometric recording of indicator dilution in an arterial cross

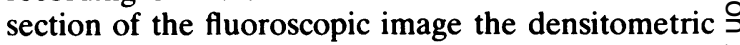
window replaces the sampling catheter used with the $\rightarrow$ conventional Stewart-Hamilton technique. ${ }^{23}$ There is one important difference in recording characteris- N tics between the Stewart-Hamilton technique and the video dilution technique. In addition to indicator concentration $(c)$ the densitometer measures the $\omega$ cross sectional volume $(v)$ at the sampling site. As concentration and volume represent the mass $(m)$ of $\mathscr{C}$ contrast $(m=c \times v)$, the densitometric recording $\mathbb{D}$ represents a mass-time curve as opposed to the + concentration-time curve obtained by catheter sam- $\frac{T}{T}$ pling. Thus the integrated area, $A$, under the mass- $\frac{\vec{D}}{\mathrm{D}}$ time curve will then be $\mathrm{k}_{1} \int m \times d t$, where the con- $\stackrel{\bigcirc}{\square}$ stant $k_{1}$ accounts for radiographic and electronic $\stackrel{\odot}{\varnothing}$ conversion factors. The area reflects the flow at the 
injection site and the cross sectional volume at the sampling site. Use of the same recording site for comparison of different proximal flows allows cross sectional volume of the vessel and temporal and density uncertainties of the contrast bolus to be ignored. The small area of interest represented by the densitometric window reduces considerably the requirements for data acquisition and storage and the flow estimates can be read on line. The integrated area, $A$, is the basis for the calculation of blood flow by the video dilution technique. If the conditions at the recording site are kept constant (radiation intensity, video densitometric window size, position of image intensifier and object), the integrated densitometric area, $A$, is directly proportional to the amount of injected contrast material, $M$, and inversely proportional to the flow, $\dot{\mathrm{Q}}$, at the injection site. $A=M / \dot{\mathrm{Q}} \times \mathrm{k}_{2}$ or $\dot{\mathrm{Q}}=M / A \times \mathrm{k}_{2}$, where $k_{2}$, which implicitly depends on vessel diameter, is a calibration constant. The constancy of vessel diameter can be verified on the radiographic image. As $k_{2}$ cannot be easily determined, flow, $\dot{Q}$, is expressed in arbitrary units. After two contrast injections, $\left(M_{1}, M_{2}\right)$ at two separate sites in a flow system, the integrated areas $\left(A_{1}, A_{2}\right)$ recorded at the same distal measuring site will reflect the flows $\left(\dot{Q}_{1}\right.$, $\dot{\mathrm{Q}}_{2}$ ) at the two injection sites. $\dot{\mathrm{Q}}_{1}=M_{1} / A_{1} \times \mathrm{k}_{2}$ and $\dot{\mathrm{Q}}_{2}=M_{2} / A_{2} \times \mathrm{k}_{2}$ where $\dot{\mathrm{Q}}_{1}$ and $\dot{\mathrm{Q}}_{2}$ are expressed in arbitrary units. The ratio can then be described $\mathrm{Q}_{1} / \mathrm{Q}_{2}=M_{1} \times A_{2} / M_{2} \times A_{1}$. For further details the reader is directed to previous reports. ${ }^{21}{ }^{24-26}$

A practical example of determination of $\dot{Q} B$ as a percentage of cardiac output should clarify the details of the technique. After insertion of the aortic root catheter and the bronchial artery catheter during fluoroscopic control, the image intensifier was focused over an area of the bronchial artery which was free from crossing vessels such as the intercostal arteries. Then $0.5 \mathrm{ml}$ of contrast agent was injected into the bronchial artery and a recording was made on videotape with respiration suspended at end expiration. After two minutes a $20 \mathrm{ml}$ pressure injection was performed in the aortic root and the passage of contrast recorded on videotape with the image intesifier focused over the identical area of the bronchial artery. The videotape was then replayed and a densitometric window placed over a cross section of the bronchial artery. A second densitometric window was placed in a neutral area. This second window served to record possible variation in radiation intensity or cardiac motion to be subtracted from the readings of the window covering the bronchial artery (fig 2 ). Recordings from the bronchial artery and the aortic root injections were displayed (fig 3). QB was calculated by the densitometer, the amount of injected contrast and the integrated area under the curve being taken into account (for example, $\dot{Q B}=23$ ). Flow in the aortic root was calculated in a similar way after integration of the dilution curve (for example $\dot{Q} A=$ 4021 ). Thus the relative flow in the bronchial artery compared to the cardiac output in the example is $23 / 4021 \times 100=0.6 \%$. If the cardiac output in absolute units determined by thermal dilution technique immediately before the two contrast injections was $4800 \mathrm{ml} / \mathrm{min}$, then QB would be $28.8 \mathrm{ml} / \mathrm{min}$.

\section{Results}

The bronchial blood flow ( $\mathrm{QB}$ ) was less than $1 \%$ of the cardiac output in each of the five sheep (table).
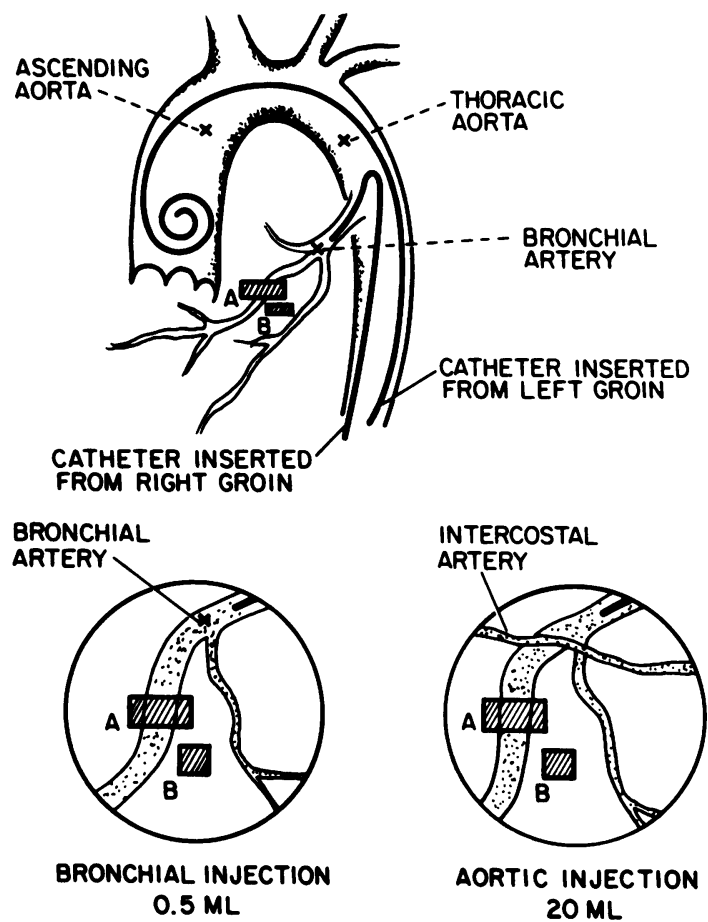

Fig 2 Above: Diagram showing selective catheter in bronchial artery and pigtail catheter in ascending aorta. Window $A$ is covering a cross section of the broncho-oesophageal artery recording the mass-time curves after the aortic and selective injections. Window $B$ is positioned in a neutral area and records possible variations of $x$ ray intensity, breathing, and cyclic heart motions of the animal. Such variations of the baseline are electronically subtracted from the parallel (synchronous) recordings in window $A$.

Below: Diagram to illustrate the importance of ensuring that other arteries from the aorta-that is, intercostal arteriesare not found to be crossing over any of the windows after aortic injections. 


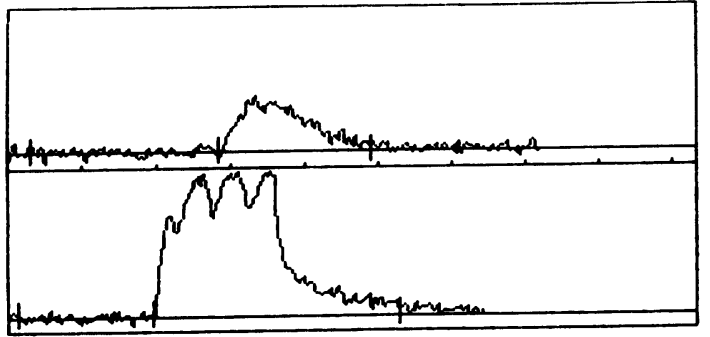

Fig 3 Video dilution technique recordings over cross section of bronchial artery after selective aortic root (above) and broncho-oesophageal artery (below) injections of contrast medium (20 and $0.5 \mathrm{ml}$ respectively).

The mean flow in 27 determinations was $0.62 \%$ (SD $0.20 \%$ ) of cardiac output, or $28.5(7.0) \mathrm{ml} \mathrm{min}^{-1}$ when matched with the corresponding cardiac output determination. The cardiac output was stable throughout each experiment, which lasted several hours (fig 4).

In sheep 2 we assessed the applicability of the video dilution technique as a means of measuring changes in QB. We injected intra-arterially adrenaline $(4.5 \mu \mathrm{g})$, histamine $(4.5$ and $90 \mu \mathrm{g})$ and histamine $(90 \mu \mathrm{g})$ with methacholine $(4.5 \mu \mathrm{g})$. A decrease in QB was observed 30 seconds after an injection of adrenaline. The low dose of histamine almost doubled QBB. A high dose of histamine $(90 \mu \mathrm{g})$ increased Q́B to 3-4\% of cardiac output and in combination with methacholine $\dot{Q B}_{B}$ increased further to about $4-5 \%$, also within 30 seconds. QB returned to normal values within five minutes.

The effect of the presence of the catheter itself was investigated in five additional sheep. No 5 French catheters were passed into the bronchooesophageal artery and the descending aorta. Simultaneously measured mean aortic and bronchooesophageal artery blood pressures were 89-89, 67-62, 77-80, 68-69, and 103-104 $\mathrm{mm} \mathrm{Hg}$ respectively, suggesting that placement of the angiographic catheter at the origin of the bronchial artery had no systematic effect on blood flow in this vessel under baseline conditions.

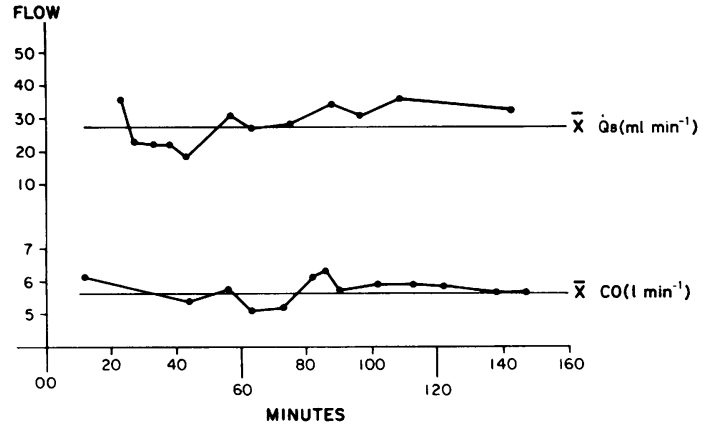

Fig 4 Example of bronchial blood flow $\left(\dot{Q}_{B}\right)$ and cardiac output (CO) measurements obtained from sheep 2 throughout the experiment. The figure shows the general stability of this preparation through the experimental period of about $2 \cdot 5$ hours.

\section{Discussion}

The purposes of the present report were, firstly, to develop a system providing for simultaneous study of anatomy and physiology of the bronchial circulation using the relatively non-invasive radiological technique of video dilution; secondly, to assess this method as a possible means of studying the determinants of airway blood flow by perturbing bronchial artery blood flow with bolus injections of histamine, cholinergic, and adrenergic stimuli; and, thirdly, to speculate on the possible importance of this blood flow in airway pathophysiology.

Anatomically, the bronchial circulation is complex in that it has a variable origin from the aorta and is distributed not only to airways but also to other intrathoracic structures such as the mediastinum and pleura. ${ }^{9}$ In the sheep the origin is less complex in that the major portion of the bronchial circulation is supplied from a single large bronchooesophageal vessel that arises from the aorta and is distributed to airways, anterior oesophagus, pleura, and mediastinum. ${ }^{91920}$ Dye injections performed as a part of the present study confirmed that this vessel supplied all of the major airways except for variable distribution to the right upper lobe. In agreement

Cardiac output $(\mathrm{CO})$ and total bronchial blood flow $\left(\dot{Q}_{B}\right)$ in five anaesthetised sheep determined by video dilution technique

\begin{tabular}{|c|c|c|c|c|c|}
\hline \multirow[t]{2}{*}{ Sheep } & \multirow{2}{*}{$\begin{array}{l}\text { Weight } \\
\mathrm{kg}\end{array}$} & \multirow{2}{*}{$\begin{array}{l}\operatorname{Mean}(S D) C O \\
\left(\operatorname{lmin}^{-1}\right)\end{array}$} & \multicolumn{3}{|c|}{ Mean $(S D)$ total $(\dot{Q} B)$} \\
\hline & & & $\%$ of $C O$ & $m l \min ^{-1}$ & $m l \min ^{-1} \mathrm{~kg}^{-1}$ \\
\hline $\begin{array}{l}1 \\
2 \\
3 \\
4 \\
5\end{array}$ & $\begin{array}{l}36 \cdot 3 \\
44 \cdot 5 \\
45 \cdot 3 \\
36 \cdot 4 \\
36 \cdot 3\end{array}$ & $\begin{array}{l}4.36(0.86) \\
5.62(0.70) \\
7.22(1.09) \\
3.25(0.38) \\
5.44(0.59)\end{array}$ & $\begin{array}{l}0.55(0.08) \\
0.49(0.12) \\
0.59(0.02) \\
0.85(0.16) \\
0.54(0.14)\end{array}$ & $\begin{array}{l}24 \cdot 1(3 \cdot 4) \\
27 \cdot 7(7 \cdot 0) \\
42 \cdot 8(1 \cdot 13) \\
27 \cdot 4(5 \cdot 1) \\
29 \cdot 4(7 \cdot 4)\end{array}$ & $\begin{array}{l}0.66(0.09) \\
0.62(0.16) \\
0.95(0.02) \\
0.75(0.14) \\
0.81(0.20)\end{array}$ \\
\hline $\begin{array}{l}\text { Mean (SD) } \\
n\end{array}$ & $\begin{array}{l}39 \cdot 8(4 \cdot 2) \\
5\end{array}$ & $\begin{array}{l}5 \cdot 18(1 \cdot 33) \\
110\end{array}$ & $\begin{array}{l}0.62(0.20) \\
27\end{array}$ & $\begin{array}{l}28 \cdot 5(7 \cdot 0) \\
27\end{array}$ & $\begin{array}{l}0 \cdot 71(0 \cdot 17) \\
27\end{array}$ \\
\hline
\end{tabular}

n

5

110 
with another recent study, ${ }^{19}$ the bronchooesophageal artery does not appear to contribute a large fraction of its flow either to the anterior oesophageal or to pleural and mediastinal stuctures. Thus this vessel appears to be a reliable approach for selective quantitative angiographic assessments of the sheep airway circulation.

The influence of our model and technique on the results has to be discussed. We used intubated, anaesthetised, and paralysed animals with positive pressure ventilation to keep blood gases in the normal range. Previous studies have shown that anaesthesia diminishes pulmonary reflexes, including bronchoconstrictor $^{27}$ and pulmonary vascular ${ }^{28}$ responses to histamine. Other workers have shown that tracheal intubation increases $\dot{Q}^{29}$ and that positive pressure ventilation reduces it. ${ }^{30}{ }^{31}$ We have no data that would contribute directly to these confounding variables. We considered the possibility that the presence of the broncho-oesophageal catheter could alter QB. Simultaneous measurements of flow by a different technique would have provided confirmation, by allowing comparison of video dilution technique determinations of blood flow with flowmeter measurements of flow in the same way that we have studied other regional circulations..$^{21}{ }^{25}$ We believe, however, that obstruction artefacts on the resting bronchial artery flow determinations are largely excluded by the fact that (1) no systematic differences were noted between simultaneously measured aorta and the broncho-oesophageal artery pressure; (2) no changes in bronchial blood flow occurred with time (fig 4) as might be expected if catheter induced "vasospasm" had occurred; and (3) our measurements of bronchial artery flow are reasonably consistent with flow determinations made by other investigators using a variety of other techniques.

Radiographic contrast media have been shown to induce haemodynamic effects, possibly via localised histamine release. ${ }^{32}$ We found that our contrast agent induced bronchial artery vasodilation $15 \mathrm{sec}-$ onds after an injection, but there was a return to baseline flow after about 60 seconds. This effect occurs after the flow data have been obtained and does not interfere with the measurement from a single injection. A two minute interval between injections is required to assure return to baseline flow concentrations. ${ }^{21}$ In unreported studies using one of the newer non-ionic contrast agents (iohexol) no or little vasodilatory effect on QB was noted (Lantz BMT, unpublished observations). The densitometric window measures the contrast agent in the entire cross section of the vessel, avoiding the sampling errors caused by inadequate mixing that may occur with conventional indicator dilution techniques.

A change in calibre of the bronchial artery segment covered by the electronic window during two consecutive recordings would introduce an error necessitating correction. ${ }^{24}$ The actual vessel diameter within the window can easily be measured from the video signal by oscilloscope. Ninety-one such measurements of bronchial artery diameter after aortic and selective bronchial artery contrast injections in these five sheep did not show any significant changes. In addition, we did not encounter any demonstrable episodes of catheter induced "vasospasm" during the experiments. Likewise, no significant changes in diameter could be measured after histamine, adrenaline, or methacholine injections. Since the constancy of the vessel diameter is so critical to the validity of the flow calculation, it is important to appreciate to major sources of error in these measurements-that is, the video acuity of the system and human measurement error. Using the worst possible case, we estimate variability in reading of the vessel diameter to be about $\pm 5 \%$, yielding a calculated flow error of less than $10 \%$.

Although many different methods have been used to assess QB, none of them is entirely satisfactory. ${ }^{916}$ The older methods, many of which made use of aortic pouches or double heart-lung bypass preparations, ${ }^{, 1316}$ are technically cumbersome. More recently reported techniques require either thoracotomy and mediastinal dissection ${ }^{19}$ or injections of radioactive microspheres, with the subsequent need to obtain airway and lung parenchymal tissues. ${ }^{15-18}$ An added complexity is that in most large experimental animals and in man several small bronchial arteries constitute the total QB.$^{9} 20$

The present values measured in our relatively non-invasive preparation can be compared with values given in recent publications. For example, in a recent study using an electromagnetic flowmeter around the bronchial artery in sheep with an open thorax, QB values of $0.4 \%$ of cardiac output were reported. ${ }^{19}$ This compares reasonably well with the current values of $0.6 \%$ of cardiac output. The small discrepancy could possibly be explained by the fact that cardiac outputs were nearly $50 \%$ lower in the open thorax flowmeter group, by technical and preparative model differences, or by differences in the regional distributions of the measured blood flows. For example, in our sheep variable small oesophageal branches and right upper lobe distributions of flow were measured, whereas the flowmeter study measured flow in vessels that were not distributed to the right upper lobe. ${ }^{19}$ Studies using microspheres in the anaesthetised dog have reported QB values representing $1.6 \%^{15}$ and $1.0 \%{ }^{16}$ of car- 
diac output. One recent microsphere study using unanaesthetised sheep has reported Q̇B values representing $2.5 \%$ of cardiac output. ${ }^{18}$ Explanations of higher flows recorded after microsphere injections include scoring of non-bronchial artery collateral vessel flows to the airways and technical problems related to corrections for recirculation effects and for shunt flows.

Data were obtained after intra-arterial bolus injections of histamine, methacholine, and adrenaline in qualities insufficient to affect systemic haemodynamics with the object of assessing the feasibility of using the video dilution technique to measure changes in QB. As has been reported by others using different experimental preparations, ${ }^{9-13}$ histamine and methacholine gave rise to impressive increases in flow, whereas adrenaline reduced flow. So far no attempts to study the dose-response patterns, time course, or mechanisms of responses to these agents have been made.

Large changes in $\dot{Q}_{B}$ may have important pathophysiological implications. For example, it is generally accepted that many agents known to affect blood vessels (for example, histamine, cholinergics, adrenergics, arachidonic acid metabolites) may play an important part in the pathogenesis of allergic bronchial asthma. ${ }^{5}$ While mediator, neural, and humoral mechanisms underlying the heightened bronchoconstrictor and hypersecretory states of this condition have been extensively studied, few studies have specifically addressed the airway vasculature. A report that cold air induces significant increases in dog bronchial blood flow is interesting in this regard. ${ }^{33}$

In recent years interest in the physiology and pathology of the gastrointestinal tract circulation has increased considerably. ${ }^{34}{ }^{35}$ Such studies have emphasised the interdependence of blood flow, smooth muscle motor activity, secretory functions, and absorptive capabilities. ${ }^{34}$ We may speculate that further understandings of the bronchial circulation and its regional distribution and modulation in health and disease could be an important consideration in future studies of airway function.

This investigation was supported in part by NHLBI grant HL 31979. JFG is the recipient of the established investigator award of the American Lung Association of California. We also acknowledge the technical support provided by Jane Higgins and Jo Weber and thank $S$ Lakshminarayanan and $G$ Kramer for thoughtful comments on the manuscript.

\section{References}

1 Remy J, Arnaud A, Fardou H, Giraud R, Voisin C.
Treatment of hemoptysis by embolization of the bronchial arteries. Radiology 1977;122:33-7.

2 Jamieson SW, Baldwin J, Reitz BA, et al. Combined heart and lung transplantation. Lancet 1983;i:1130-2.

3 Guthaner DF, Wexler L, Sadeghi AM, Blank NE, Reitz BA. Revascularization of tracheal anastomosis following heart-lung transplantation. Invest Radiol 1983;18:500-3.

4 McFadden ER. Respiratory heat and water exchange: physiological and clinical implications. J Appl Physiol 1983;54:331-6.

5 Boushey HA, Holtzman MJ, Sheller JR, Nadel JA. State of the art: bronchial reactivity. Am Rev Respir Dis 1980;121:389-413.

6 Alcock P, Berry JL, de Burge Daly I, Narayana B. The action on perfused lungs of drugs injected into the bronchial vascular system. $Q J$ Exp Physiol 1936;26: 13-27.

7 Liebow AA, Hales MR, Harrison W, Bloomer W, Lindskog GE. The genesis and functional implications of collateral circulation of the lungs. Yale J Biol Med 1950;22:637-50.

8 DeKock MA, Nadel JA, Swi S. New method for perfusing bronchial arteries: histamine bronchoconstriction and apnea. J Appl Physiol 1966;21:185-94.

9 Daly IDB, Hebb C. Pulmonary and bronchial vascular systems: their reactions under controlled conditions of ventilation and circulation. London: Edward Arnold, 1966:42-88.

10 Cudkowicz W. Human bronchial circulation in health and disease. Baltimore: Williams and Wilkins, 1968:84-104.

11 Bruner HD, Schmidt CF. Blood flow in the bronchial artery of the anesthetised dog. Am J Physiol 1947;148:648-66.

12 Martinez J, Castro R, Aviado DM. Local and reflex effects of bronchial arterial injection of drugs. J Pharmacol Exp Ther 1961;133:295-304.

13 Aviado DM. The lung circulation. New York: Pergamon Press, 1965:185-254.

14 Fisher AB, Kollmeier H, Brody JS, et al. Restoration of systemic blood flow to the lung after division of $\frac{x}{\times}$ bronchial arteries. J Appl Physiol 1970;29:839-46.

15 Malik AB, Tracy SE. Bronchovascular adjustments after pulmonary embolism. J Appl Physiol $1980 ; 49: 476-81$.

16 Baile EM, Nelems JMB, Schulzer M, Pare PD. Measurement of regional bronchial artery blood flow and $\bigcirc$ bronchovascular resistance in dogs. J Appl Physiol 1982;53:1044-9.

17 Baile EM, Pare PD. Response of the bronchial circulation to acute hypoxemia and hypercarbia in the dog. $J$ o Appl Physiol 1983;55:1474-9.

18 Kramer GC, Cross CE, Herndon DN, Tauber DL. Dis- N tribution of bronchial blood flow in unanesthetised $N_{\omega}^{N}$ sheep measured with a double microsphere technique. 0 Fed Proc 1984;43:921.

19 Magno MG, Fishman AP. Origin, distribution, and blood flow of bronchial circulation in anesthetized $\mathscr{Q}$ sheep. J Appl Physiol 1982;53:272-9.

20 Anderson WD. Thorax of sheep and man. Min- $T$ neapolis: Dillon Press, 1971:36.

21 Lantz BMT, Foerster JM, Link DP, Holcroft JW. Determination of relative blood flow in single arteries: $\overrightarrow{\mathbb{D}}$ new video dilution technique. AJR 1980;134:1161-8.

22 Nakahara K, Ohkuda K, Staub NC. Effect of infusing 
histamine into pulmonary or bronchial artery in sheep pulmonary fluid balance. Am Rev Respir Dis 1979; 120:875-82.

23 Fox IJ. Indicators and detectors for circulatory dilution studies and their application to organ or regional blood flow determination. Circ Res 1962;10:447-71.

24 Lantz BMT. Relative flow measured by roentgen videodensitometry in hydrodynamic model. Acta Radiol [Diagn] (Stockh) 1975;16:503-19.

25 Holcroft JW, Lantz BMT, Link DP, Foerster JM. Video dilution technique accurately measures blood flow. Surg Forum 1980;31:324-5.

26 Lantz BMT. Quantitative angiography by video dilution technique. Appl Radiol 1984;13:90-7.

27 Jackson DM, Richards IM. The effects of pentobarbitone and chloralose anesthesia on the vagal component of bronchoconstriction produced by histamine aerosol in anesthetized dogs. $\mathrm{Br} J$ Pharmacol 1977;61:251-6.

28 Woods JR, Brinkman CR, Dandavino A, Murayama $\mathrm{K}$, Assali NS. Action of histamine and $\mathrm{H}_{1}$ and $\mathrm{H}_{2}$ blockers on the cardiopulmonary circulation. Am J Phys Med 1977;232:H73-8.
29 Nordin U, Lindholm C-E, Wolgast M. Blood flow in the rabbit tracheal mucosa under normal conditions and under the influence of tracheal intubation. Acta Anesthesiol Scand 1977;21:81-94.

30 Barie PS, Hakim TS, Malik AB. Effect of pulmonary artery occlusion and reperfusion on extravascular fluid accumulation. J Appl Physiol 1981;50:102-6.

31 Baile EM, Albert RK, Kirk W, Lakshminarayan S, Wiggs JR, Pare PD. Positive end-expiratory pressure decreases bronchial blood flow in the dog. J Appl Physiol 1984;56:1289-93.

32 Rockoff SD, Brasch R. Contrast medial as histamine liberators. III. Histamine release and some associated hemodynamic effect during pulmonary angiography in the dog. Invest Radiol 1971;6:110-4.

33 Baile EM, Dahlby RW, Wiggs BR, Pare PD. Mechanisms for cold-air-induced increase in airway blood flow. Fed Proc 1984;43:921.

34 Fielding LP, ed. Gastro-intestinal mucosal blood flow. Edinburgh: Churchill Livingstone, 1980.

35 Granger DN, Bulkley GB, eds. Measurement of blood flow, applications to the splanchnic circulation. Baltimore: Williams and Wilkins, 1981. 